\title{
THE BINDER JETTING OF Nb-BASED IN-SITU COMPOSITE
}

\author{
Ivan GONCHAROV, Liliya HISAMOVA, Liana SAUBANOVA, Nikolay RAZUMOV, Igor POLOZOV, \\ Anatoly POPOVICH
}

\author{
Peter the Great St. Petersburg Polytechnic University, Russian Federation, 9670522@mail.ru
}

https://doi.org/10.37904/metal.2019.938

\begin{abstract}
The $\mathrm{Nb}-\mathrm{Si}$ in-situ composite was synthesized by binder jetting additive manufacturing technology. The $\mathrm{Nb}$ powder was used as the raw material. The green model was printed with binder in a layer-by-layer way and then infiltrated with liquid Si during in furnace. The microstructure consists of $\mathrm{NbSi}_{2}$ and excess silicon. To control the $\mathrm{Si}$ content a mixture of $\mathrm{Nb}-16 \mathrm{Si}(\mathrm{at} \%)$ was used as a raw material with subsequent melting of internal silicon in the furnace. As a result, the microstructure consists of $\mathrm{Nb}_{s s}, \mathrm{Nb}_{3} \mathrm{Si}, \mathrm{NbSi}_{2}$ phases.
\end{abstract}

Keywords: Additive manufacturing, binder jetting, in-situ composites, Nb-Si

\section{INTRODUCTION}

$\mathrm{Nb}$-Si-based alloys have shown high potential to replace Ni-based superalloys due to their high melting point, low density as well as attractive specific mechanical properties at elevated temperatures [1-3]. However, Nb$\mathrm{Si}$ based alloys are still limited by their poor room-temperature fracture toughness and insufficient hightemperature oxidation resistance [4,5]. Improvement in mechanical and environmental properties will be achieved by alloying with several elements and the development of advanced processing and production technologies. The main problems of casting technologies for obtaining these materials are microstructural inhomogeneity, as well as problems associated with the complexity of casting materials with high melting point [6]. Conventional powder technologies based on pressing and sintering do not allow achieving the required density of compact material. For powder technology, there is also the problem of obtaining products of complex shape. Additive manufacturing technologies look like the most promising way to solve the problem of using high-temperature in-situ composites as high-temperature materials. For additive manufacturing technology of selective laser melting (SLM) and direct energy deposition (DED) [7], there are problems in the form of a hightemperature gradient during the process, which leads to the formation of cracks. The binder jetting technology with subsequent infiltration and heat treatment may be the technology that can help to avoid many of the drawbacks of both casting and powder technologies.

\section{MATERIALS AND METHODS}

Studies were conducted using niobium powder fraction with $45 \mu \mathrm{m}$, Fabrication was achieved by the binder jetting process using the ExOne Innovent system. The process consists of fabricating three-dimensional parts from raw powder material. Powders are bonded together layer-by-layer. The ExOne Innovent printer consists of a two-bed system as shown in Figure 1; one bed is for the base powder material and the other for part fabrication. Powder layers are spread with a roller. Once the powder layer is uniformly spread, the powder bed returns to its original position where binder droplets are selectively deposited through a piezoelectric printhead for part fabrication. Once the binder is deposited, the powder bed moves below the heater, where heat is provided for a set amount of time to achieve powder binding. This is considered as the fabrication of one layer, and the process continues until part fabrication is complete. After fabrication is finished, the building envelope is placed in the oven at $195^{\circ} \mathrm{C}$ for $2 \mathrm{~h}$. This step is performed to cure the binder selectively placed in the fabricated part, allowing the separation of the fabricated geometry from the unbound powder. After the binder is cured, the parts are brushed to remove unbound powder and prepared for infiltration. 


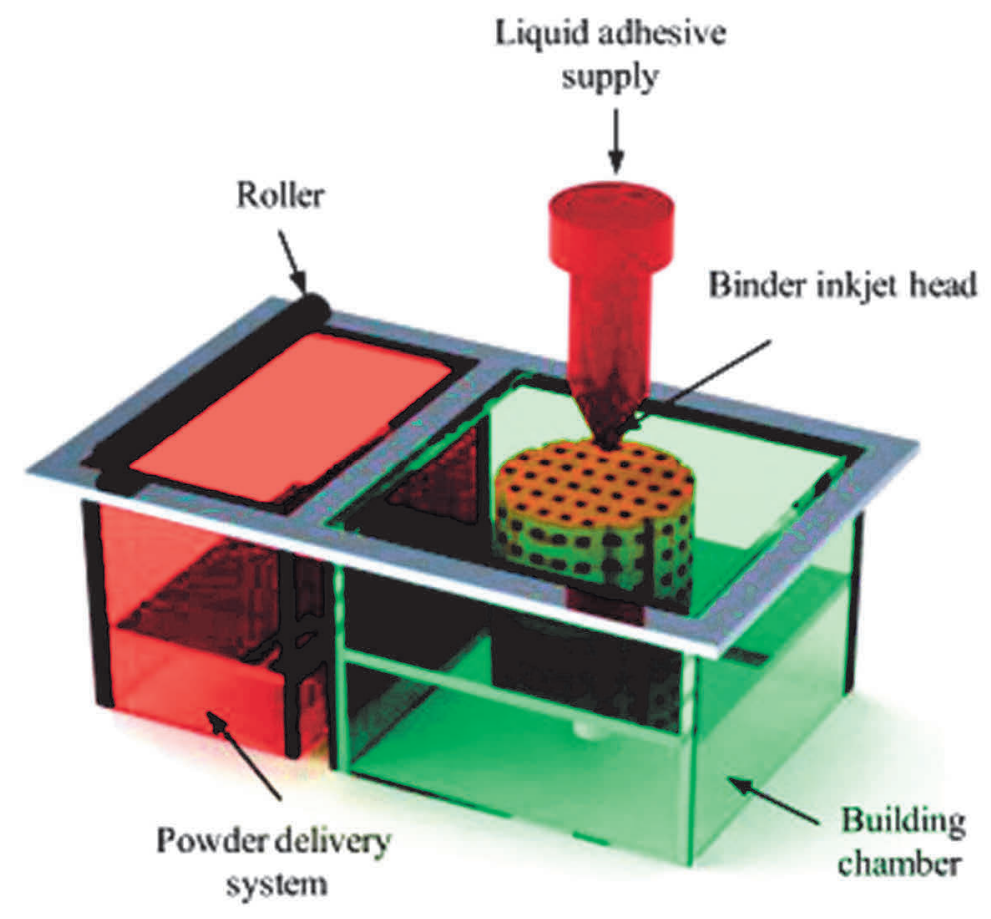

Figure 1 Binder jetting technology schematic [8]

\section{RESULTS AND DISCUSSION}

Figure 2a shows the backscatter electron (BSE) photographs of the sample after Si infiltration. It consists of dispersed light near-equiaxed areas surrounded by continuous dark matrix. After heat treatment at $1400{ }^{\circ} \mathrm{C}$ for 6 hours there is no significant difference in microstructure (Figure $\mathbf{2 b}$ ). The elemental mapping made by SEM is shown in Figure 2c. It indicates the presence both $\mathrm{Nb}$ and $\mathrm{Si}$ in dispersed light areas, whereas dark matrix consists of $\mathrm{Si}$.

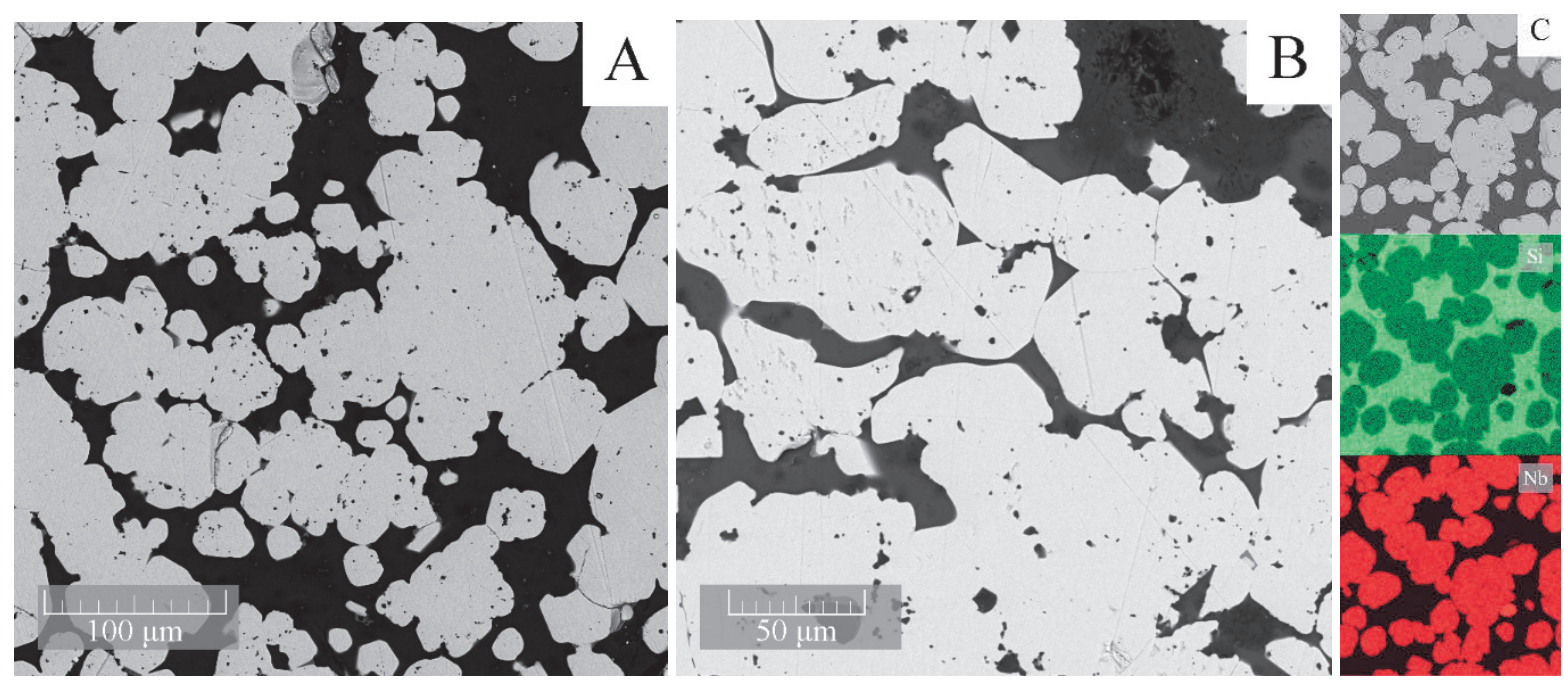

Figure 2 Microstructure of the $\mathrm{Nb}-\mathrm{Si}$ sample a) after infiltration

b) after heat treatment $1400^{\circ} \mathrm{C}$ for 6 hours $\mathrm{c}$ ) elemental mapping

The ratio of the content of elements corresponding to the silicide phase of $\mathrm{NbSi}_{2}$ in the light region and $\mathrm{Si}$ in the dark phase showed an EDS analysis of chemical elements (Figure 3a, Table 1). During the process of infiltration by liquid silicon of the sample of niobium powder, the latter fully reacts by the reaction: 
$\mathrm{Nb}+\mathrm{Si} \rightarrow \mathrm{NbSi}_{2}$. The excess of the silicon forms the dark matrix. It appears that the key parameter of the formation of the in-situ composite is the amount of silicon, fed during the infiltration process.
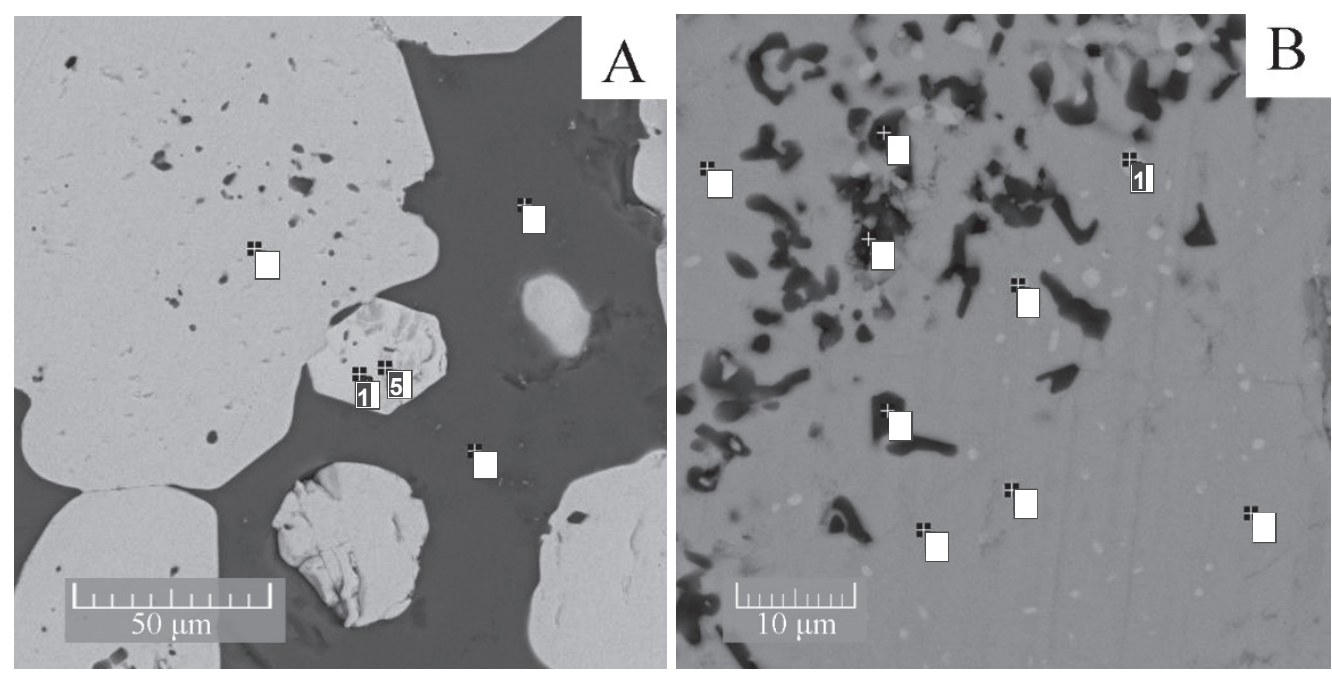

Figure 3 EDS Point analysis of the Nb-Si sample a) after infiltration

b) after inner silicon melting without infiltration

Table 1 Elemental mass concentration for the constituent phases of samples

\begin{tabular}{|c|c|c|c|c|c|c|}
\hline \multirow[b]{2}{*}{ Point } & \multicolumn{3}{|c|}{ Sample after infiltration } & \multicolumn{3}{|c|}{ Sample after inner silicon melting } \\
\hline & $\begin{array}{c}\text { Nb content } \\
(\text { at } \%)\end{array}$ & $\begin{array}{l}\text { Si content } \\
(\text { at } \%)\end{array}$ & Phase & $\begin{array}{c}\text { Nb content } \\
(\text { at } \%)\end{array}$ & Si content (at $\%)$ & Phase \\
\hline 1 & 33.6 & 66.4 & \multirow{2}{*}{$\mathrm{NbSi}_{2}$} & 67.9 & 32.1 & \multirow{3}{*}{$\mathrm{Nb}_{5} \mathrm{Si}_{3}$} \\
\hline 2 & 32.8 & 67.2 & & 61.7 & 38.3 & \\
\hline 3 & 0 & 100 & \multirow{2}{*}{ Si } & 54.0 & 46.0 & \\
\hline 4 & 0 & 100 & & 13.9 & 86.1 & \\
\hline 5 & 34.1 & 65.9 & $\mathrm{NbSi}_{2}$ & 14.5 & 85.5 & \\
\hline 6 & - & - & & 13.5 & 86.5 & \\
\hline 7 & - & - & & 33.8 & 66.2 & \multirow{3}{*}{$\mathrm{NbSi}_{2}$} \\
\hline 8 & - & - & & 33.8 & 66.2 & \\
\hline 9 & - & - & & 33.7 & 66.3 & \\
\hline
\end{tabular}

To control the feed of the silicon, the composition of $\mathrm{Nb}-16 \mathrm{Si}$ (at\%) was determined. The mechanical mixture of powders was uniformly mixed, and then the sample was fabricated using the binder jetting technology. The melting of silicon contained in the mixture was carried out in the furnace at a temperature of $1460{ }^{\circ} \mathrm{C}$ without infiltration of extra silicon.

Figure 4a shows the backscatter electron (BSE) photographs of the sample after inner Si melting. It is presented by non-sintered powder particles, contained three regions: dark phases, dispersed in gray main phase, and light gray areas. According to the elemental mapping distribution (Figure 4b), part of silicon diffuses into particles of the niobium matrix, forming dispersed zones of free silicon. The rest of the silicon reacts with $\mathrm{Nb}$ matrix. According to the EDS analysis of chemical elements by points (Figure 3b, Table 1), the microstructure consists of three main phases: light - niobium silicide $\mathrm{Nb}_{3} \mathrm{Si}$, gray - niobium silicide $\mathrm{NbSi}_{2}$, and dark - Si which are typical for Nb-Si binary phase diagram [9]. 


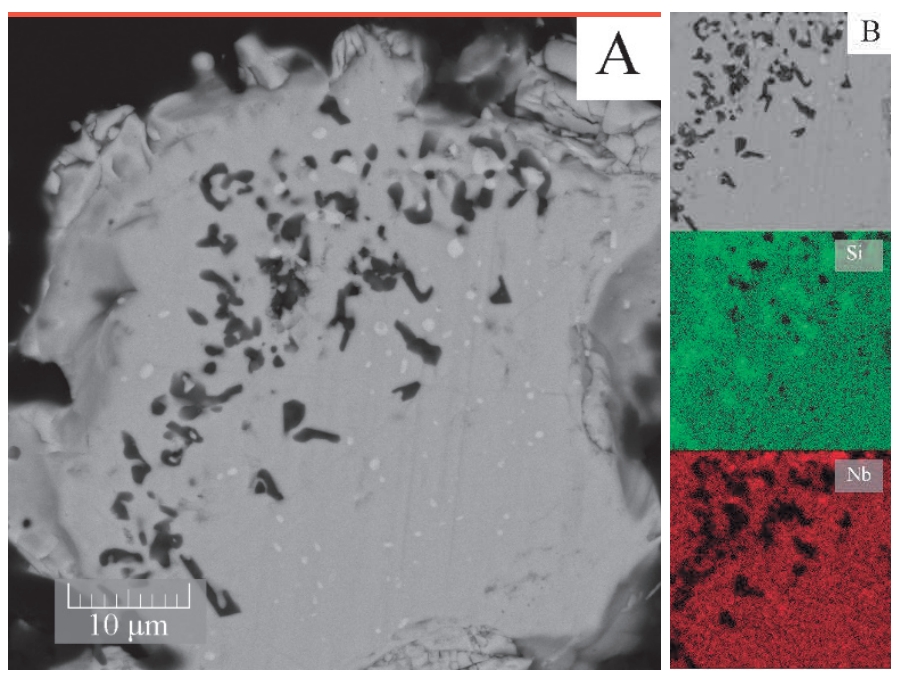

Figure 4 Microstructure of the Nb-Si sample a) after inner silicon melting without infiltration heat treatment b) elemental mapping

\section{CONCLUSION}

In this work, a synthesis of the Nb-Si based in-situ composite by binder jetting technology was investigated.

The samples of $\mathrm{Nb}-\mathrm{Si}$ composite were obtained by binder jetting of $\mathrm{Nb}$ powder and infiltration with liquid $\mathrm{Si}$. The microstructure consists of $\mathrm{NbSi}_{2}$ phase dispersed in the continuous Si phase matrix.

The key parameter of the formation of the in-situ composite is seemed to be the amount of silicon, fed during the infiltration process.

The samples of $\mathrm{Nb}-16 \mathrm{Si}(\mathrm{at} \%)$ were obtained by binder jetting of $\mathrm{Nb}+\mathrm{Si}$ powder mixture and melting inner silicon in the furnace at $1460{ }^{\circ} \mathrm{C}$ without infiltration. The microstructure of the sample consists of three phases: $\mathrm{Nb}_{5} \mathrm{Si}_{3}, \mathrm{NbSi}_{2}$, and $\mathrm{Si}$.

\section{ACKNOWLEDGEMENTS}

The reported study was funded by RFBR according to the research project № 18-33-00850

\section{REFERENCES}

[1] LIU, C.M., WANG, H.M., ZHANG, S.Q., TANG, H.B. and ZHANG, A.L. Microstructure and oxidation behavior of new refractory high entropy alloys. J. Alloys Compd. 2014, vol. 583, pp. 162-169.

doi:10.1016/j.jallcom.2013.08.102.

[2] BEWLAY, B.P., JACKSON, M.R., ZHAO, J.-C., SUBRAMANIAN, P.R. MENDIRATTA, M.G. and LEWANDOWSKI, J.J.Ultrahigh-temperature Nb-silicide-based composites. MRS Bull. 2003. vol. 28, pp. 646-653. doi:10.1557/mrs2003.192.

[3] POPOVICH, A.A., RAZUMOV, N.G. GRIGORIEV, A.V., SAMOKHIN, A. V., SUFIYAROV, V.S., GONCHAROV, I.S., FADEEV, A.A. and SINAISKII, M.A. Fabrication of the $\mathrm{Nb}-16 \mathrm{Si}$ alloy powder for additive technologies by mechanical alloying and spheroidization in electric-arc discharge thermal plasma. 2018, vol. 59, pp. 671-676. doi:10.3103/S1067821218060160.

[4] GUO, Y., JIA, L., ZHANG, H., ZHANG, F. and ZHANG, H. Enhancing the oxidation resistance of Nb-Si based alloys by yttrium addition, Intermetallics. 2018. vol. 101, pp. 165-172. doi:10.1016/J.INTERMET.2018.08.004.

[5] SEKIDO, N., KIMURA, Y., MIURA, S. WEI, F.-G. and MISHIMA, Y.Fracture toughness and high temperature strength of unidirectionally solidified Nb-Si binary and Nb-Ti-Si ternary alloys. J. Alloys Compd. 2006. vol. 425, pp. 223-229. doi:10.1016/J.JALLCOM.2006.01.071. 
[6] SVETLOV, I.L. High-temperature Nb-Si composites. Part 1. Inorg. Mater. Appl. Res. 2011. no. 2, pp. $307-315$.

[7] SUfIIAROV, V.S., POPOVICH, A.A., BORISOV, E.V., POLOZOV, I.A., MASAYLO, D.V., ORLOV, A.V. The effect of layer thickness at selective laser melting. Procedia Eng. 2017. vol. 174, pp. 126-134.

[8] FRIEL, R.J. Power ultrasonics for additive manufacturing and consolidating of materials. Power Ultrason. 2015. pp. 313-335. doi:10.1016/B978-1-78242-028-6.00013-2.

[9] ZHAO, C., BEWLAY, B.P., JACKSON, M.R. and PELUSO, L.A. Alloying and phase stability in niobium silicide insitu composites. In Proc. of 3rd Int. Symp. Struct. Intermet. 2001. p. 483. 